\title{
Correction to: Prevention of Intra-abdominal Adhesions by Electrical Stimulation
}

\author{
Ildar R. Fakhradiyev ${ }^{1}$ - Ydyrys Almabayev ${ }^{1} \cdot$ Timur Saliev $^{1} \cdot$ Aygul Almabayeva $^{2}$. \\ Baimakhan Tanabayev $^{3} \cdot$ Maral Yergazina $^{1} \cdot$ Zhandos Serikpayev $^{1} \cdot$ Loreto B. Feril Jr. $^{4}$
}

Published online: 18 May 2020

(C) Société Internationale de Chirurgie 2020

Correction to: World J Surg

https://doi.org/10.1007/s00268-020-05508-z

In the original version of this article, Ydyrys Almabayev's, Timur Saliev's, Aygul Almabayeva's, Baimakhan Tanabayev's, Maral Yergazina's, and Zhandos Serikpayev's first and last names were transposed.

The original article has been updated.

Publisher's Note Springer Nature remains neutral with regard to jurisdictional claims in published maps and institutional affiliations.

The original article can be found online at https://doi.org/10.1007/ s00268-020-05508-z.

$\triangle$ Ildar R. Fakhradiyev

Fakhradiyev.i@kaznmu.kz

1 Laboratory of Experimental Medicine, S.D. Asfendiyarov Kazakh National Medical University, 94, Tole-bi Str., Almaty 050000, Republic of Kazakhstan

2 Astana Medical University, 49a Beibitshilik St., Nur-Sultan 010000, Republic of Kazakhstan

3 South-Kazakhstan Medical Academy, 1/1 Al-Farabi Square, Shymkent 160019, Republic of Kazakhstan

4 Department of Anatomy, Fukuoka University School of Medicine, Nanakuma Jonan-ku, Fukuoka, Japan 